\title{
Cigarette smoking, genetic polymorphisms and colorectal cancer risk: the Fukuoka Colorectal Cancer Study
}

\author{
Hoirun Nisa*1, Suminori Kono', Guang Yin'1, Kengo Toyomura', Jun Nagano', Ryuichi Mibu², Masao Tanaka², \\ Yoshihiro Kakeji3 ${ }^{3}$ Yoshihiko Maehara3 ${ }^{3}$ Takeshi Okamura4 ${ }^{4}$ Koji Ikejiri5, Kitaroh Futami6, Takafumi Maekawa6, \\ Yohichi Yasunami7, Kenji Takenaka ${ }^{8}$, Hitoshi Ichimiya ${ }^{9}$ and Reiji Terasaka10
}

\begin{abstract}
Background: It is uncertain whether smoking is related to colorectal cancer risk. Cytochrome P-450 CYP1A1, glutathione-S-transferase (GST) and NAD(P)H:quinone oxidoreductase 1 (NQO1) are important enzymes in the metabolism of tobacco carcinogens, and functional genetic polymorphisms are known for these enzymes. We investigated the relation of cigarette smoking and related genetic polymorphisms to colorectal cancer risk, with special reference to the interaction between smoking and genetic polymorphism.

Methods: We used data from the Fukuoka Colorectal Cancer Study, a population-based case-control study, including 685 cases and 778 controls who gave informed consent to genetic analysis. Interview was conducted to assess lifestyle factors, and DNA was extracted from buffy coat.

Results: In comparison with lifelong nonsmokers, the odds ratios (OR) of colorectal cancer for $<400,400-799$ and $\geq 800$ cigarette-years were 0.65 (95\% confidence interval [Cl], 0.45-0.89), 1.16 (0.83-1.62) and 1.14 (0.73-1.77), respectively. A decreased risk associated with light smoking was observed only for colon cancer, and rectal cancer showed an increased risk among those with $\geq 400$ cigarette-years (OR 1.60, 95\% Cl 1.04-2.45). None of the polymorphisms under study was singly associated with colorectal cancer risk. Of the gene-gene interactions studied, the composite genotype of CYP1A1*2A or CYP1A1*2C and GSTT1 polymorphisms was associated with a decreased risk of colorectal cancer, showing a nearly statistically significant $\left(P_{\text {interaction }}=0.06\right)$ or significant interaction $\left(P_{\text {interaction }}=0.02\right)$. The composite genotypes of these two polymorphisms, however, showed no measurable interaction with cigarette smoking in relation to colorectal cancer risk.
\end{abstract}

Conclusions: Cigarette smoking may be associated with increased risk of rectal cancer, but not of colon cancer. The observed interactions between CYP1A1 and GSTT1 polymorphisms warrant further confirmation.

\section{Background}

Both environmental and genetic factors are thought to play an important role in colorectal carcinogenesis [1]. The role of genetic factors in the etiology of colorectal cancer is estimated to be $35 \%$ in a twin study [2]. Recent genome-wide association studies have identified several novel single nucleotide polymorphisms (SNPs) associated with colorectal cancer risk, suggesting the importance of

* Correspondence: hoirun@phealth.med.kyushu-u.ac.jp

${ }^{1}$ Department of Preventive Medicine, Graduate School of Medical Sciences, Kyushu University, 3-1-1 Maidashi, Higashi-ku, Fukuoka, 812-8582, Japan Full list of author information is available at the end of the article combination of low-penetrance genes [3]. Furthermore, it is estimated that one SNP is involved in approximately $15 \%$ of colorectal cancer in European populations [4].

A large number of studies have consistently shown that cigarette smoking is associated with increased risk of colorectal adenoma, a well-established precursor lesion of colorectal cancer, as reviewed elsewhere [5,6]. The findings on smoking and colorectal cancer are inconsistent, however. While a recent meta-analysis reported a statistically significant 1.18-fold increase in the risk of colorectal cancer associated with smoking [7], individual studies showed a weak or null association between smoking and 
colorectal cancer [5,7]. For example, several studies suggested a modest increase in the risk of colorectal cancer associated with smoking [8-11], but other studies failed to find such a positive association [12-14].

Tobacco smoke contains various types of carcinogens such as polycyclic aromatic hydrocarbons (PAHs), heterocyclic amines, aromatic amines and N-nitrosamines which require metabolic activation and detoxification by different enzymatic pathways, including cytochrome P450 (CYP), glutathione-S- transferases (GSTs) and $\mathrm{NAD}(\mathrm{P}) \mathrm{H}$ :quinone oxidoreductase 1 (NQO1). CYP1A1 is a phase I, predominantly extrahepatic, microsomal enzyme involved in the bioactivation of PAHs including benzo(a)pyrene. Two functional polymorphisms are known in the CYP1A1 gene; one is $3698 \mathrm{~T}>\mathrm{C}$ substitution (CYP1A1*2A, rs 4646903) creating an MspI restriction site in the 3 '-flanking region, and the other is $2454 \mathrm{~A}>\mathrm{G}$ substitution $(C Y P 1 A 1 * 2 C$, rs 1048943$)$ resulting in an amino acid change in exon 7 (Ile462Val) [15]. The $C Y P 1 A 1 * 2 A$ and $C Y P 1 A 1 * 2 C$ alleles are putatively linked to higher inducibility of the enzyme, and some studies have suggested an increased risk of tobacco-related cancers associated with these variant alleles $[15,16]$. An increased risk of in situ colorectal carcinoma associated with $C Y P 1 A 1 * 2 A$ was reported in a small case-control study in Hawaii [17], but no association between $C Y P 1 A 1 * 2 A$ and colorectal cancer was observed in subsequent studies [18-20]. CYP1A1*2C was unrelated to colorectal cancer risk in these studies [17-20], but was associated with an increased risk in another study [21]. GSTs are a superfamily of detoxification enzymes that facilitate the inactivation of chemical carcinogens and environmental toxic compounds [22]. GSTs consist of several classes of genes, and GSTM1 and GSTT1 polymorphisms have been investigated most intensively in relation to tobacco-related cancers [22]. The null genotypes of these polymorphisms result in a complete loss of enzyme function and thus may be at increased risk of tobacco-related cancers [22]. Results on GSTM1 and GSTT1 polymorphisms in relation to colorectal cancer are inconsistent as reviewed elsewhere [23,24]. The GSTP1 gene also has a functional polymorphism, but this polymorphism is unlikely to play an important role for smoking-related cancers [25]. The NQO1 is involved in detoxification through their two electron reduction to hydroquinones, thereby inhibiting the DNA adduct formation although NQO1 can act as pro-oxidant in certain conditions [26]. The functional $609 \mathrm{C}>\mathrm{T}$ polymorphism (rs 1800566) causing amino acid change (Pro187Ser) results in loss of NQO1 activity, and may increase susceptibility to the risk of cancer, especially of tobacco-related cancers [26]. A meta-analysis suggested an increased susceptibility to colorectal cancer as well as lung and bladder cancers associated with NQO1 187Ser allele, although the results from individual studies were heterogeneous [27].

Previously, several studies have addressed the interaction between cigarette smoking and one or more of these polymorphisms on colorectal cancer risk [19,20,28-33], and some suggested an interaction between GSTT1 or GSTM1 null genotype and cigarette smoking $[28,30]$ and between $C Y P 1 A 1 * 2 A$ or $C Y P 1 A 1 * 2 C$ and cigarette smoking [19]. Few studies have addressed the gene-gene interaction between phase I and II enzymes in relation to colorectal carcinogenesis $[20,21,34]$. In the present study, we examined the relation of CYP1A1, GSTM1, GSTT1 and NQO1 polymorphisms as well as of cigarette smoking to colorectal cancer risk in the Fukuoka Colorectal Cancer Study, a community-based case-control study [35], focusing on the interaction with cigarette smoking and gene-gene interaction. This is the first study regarding combined genotypes of phase I and II enzymes and colorectal cancer risk in Japan.

\section{Methods}

The Fukuoka Colorectal Cancer Study is a case-control study of incident cases and community controls in Fukuoka City and three adjacent areas. Details of methodological issues have been described elsewhere [35]. The study protocol was approved by the ethics committees of the Kyushu University, Faculty of Medical Sciences and of all except two of the participating hospitals. The two hospitals had no ethics committees at the time of survey, and approval was obtained from the director of each hospital.

\section{Subjects}

Cases were a consecutive series of patients with histologically confirmed incident colorectal adenocarcinoma who were admitted to one of the participating hospitals (two university hospitals and six affiliated hospitals) for surgical treatment during the period September 2000 to December 2003. Eligible cases were Japanese men and women aged 20 to 74 years at time of diagnosis; lived in the study area; had no prior history of partial or total removal of the colorectum, familial adenomatous polyposis, or inflammatory bowel disease; and were mentally competent to give informed consent and to complete the interview. Of the total 1,053 eligible cases, $840(80 \%)$ cases participated in the interview, and 685 gave informed consent for the genotyping.

Controls were randomly selected from the study area by frequency-matching with respect to gender and 10year age group. Eligibility criteria for controls were the same as described for the cases except that they had no prior diagnosis of colorectal cancer. A total of 1,500 persons were selected as control candidates by a two-stage random sampling, using residential registry. They were 
invited to participate in the study by mail. Of these, 833 persons participated in the survey, and 778 gave an informed consent for the genotyping. The participation rate for the interview was calculated as $60 \%$ (833 of 1,382), after exclusion of 118 persons for the following reasons: death $(n=7)$, migration from the study area $(n=$ $22)$, undelivered mail $(\mathrm{n}=44)$, mental incompetence $(\mathrm{n}=$ 19), history of partial or total removal of the colorectum $(n=21)$ and diagnosis of colorectal cancer after the survey $(\mathrm{n}=5)$.

\section{Interview}

Research nurses interviewed cases and controls in person regarding smoking, alcohol intake, physical activity and other factors using a uniform questionnaire. Interviews for cases were conducted in hospital during admission, and those for controls were conducted mostly at public community centers or collaborating clinics. The referent time for cases was the date of the onset of symptoms or the screening, and that for controls was the time of interview. Detailed information on smoking history was ascertained by asking individuals firstly whether they had ever smoked cigarettes daily for one year or longer. Age of starting smoking and that of quitting smoking (for past smokers) were ascertained, along with years of smoking and numbers of cigarettes smoked per day for each decade of age from the second to eighth decade. Cumulative exposure to cigarette smoking until the beginning of the previous decade of age was expressed by cigaretteyears, the number of cigarettes smoked per day multiplied by years of smoking, and classified into 0, 1-399, 400-799 and >800 cigarette-years.

Alcohol consumption at the time of five years prior to the referent time was elicited. The amount of alcohol was expressed in the conventional unit; one go $(180 \mathrm{~mL})$ of sake, one large bottle $(633 \mathrm{~mL})$ of beer and half a go $(90$ $\mathrm{mL}$ ) of shochu were each expressed as one unit; and one drink $(30 \mathrm{~mL})$ of whisky or brandy and one glass $(100 \mathrm{~mL})$ of wine were each converted to a half unit. Questions on physical activities elicited type of job (sedentary or standing work, work with walking, labor walk, hard labor work and no job), activities in commuting and housework, together with leisure-time activities at the time five years previously. As described in detail previously [36], leisuretime physical activity (including activities in commuting and housework) was expressed as a sum of metabolic equivalents (MET) multiplied by hours of weekly participation in each activity.

Height (cm), recent body weight and body weight at the time 10 years before were elicited. Body mass index $(\mathrm{kg} /$ $\left.\mathrm{m}^{2}\right) 10$ years earlier was used because the current body mass index was unrelated to risk [36]. Body weight 10 years earlier was not ascertained from 2 cases and 10 controls and was substituted with the current body weight.

\section{Genotyping}

DNA was extracted from the buffy coat by using a commercial kit (Qiagen GmbH, Hilden, Germany), and genotyping was performed using the PCR-RFLP or PCR method. The PCR was performed in a reaction mixture of $10 \mu \mathrm{L}$ containing approximately $50-150 \mathrm{ng} / \mu \mathrm{L}$. Genotyping for the $C Y P 1 A 1 * 2 A$ polymorphism was analyzed by PCR-RFLP using primers 5'-TAGGA GTCTT GTCTC ATGCC T-3' (sense) and 5'-CAGTG AAGAG GTGTA GCCGC T-3' (anti-sense) [17]. The PCR product of 340 bp was digested with $M s p \mathrm{I}$, resulting in fragments of 200 and $140 \mathrm{bp}$ for the $C Y P 1 A 1 * 2 A$ allele. The $C Y P 1 A 1 * 2 C$ polymorphism was determined by the PCR-RFLP method using primers 5'-GAACT GCCAC TTCAG CTGTC T-3' (sense) and 5'-GAAAG ACCTC CCAGC GGTCA-3' (anti-sense) [37]. The PCR product of $187 \mathrm{bp}$ was cleaved into three fragments $(120,48$ and $19 \mathrm{bp})$ in the presence of the CYP1A1*2C allele, and otherwise into two fragments (139 and $48 \mathrm{bp}$ ). GSTM1 and GSTT1 polymorphisms were determined by the multiplex PCR method using primers for GSTM1, GSTT1 and albumin as described elsewhere [38]. Genotyping for NQO1 Pro187Ser was performed as described earlier [39], using primers 5'-TCTCC TCATC CTGTA CCTCT-3' (sense) and 5'-TCCTC AGAGT GGCAT TCTGC-3' (anti-sense). The PCR product of 230 bp was digested with Hinfl, resulting in fragments of 195 and 35 bp for the 187Pro allele, and in fragments of 151, 44 and $35 \mathrm{bp}$ for the 187 Ser allele.

\section{Statistical analysis}

Associations of cigarette smoking and genetic polymorphisms with colorectal cancer were examined in terms of odds ratio (OR) and 95\% confidence interval (CI) which were obtained from a logistic regression analysis. The multivariate models always included indicator variables for 5-year age class (starting with the lowest class of $<50$ years), sex, residence area (Fukuoka City or the adjacent areas), body mass index 10 years ago $(<22.5,22.5-24.9$, $25.0-27.4$ or $\left.\geq 27.5 \mathrm{~kg} / \mathrm{m}^{2}\right)$, smoking $(0,1-399,400-799$ or $\geq 800$ cigarettes-years), alcohol intake (0, 0.1-0.9, 1.0-1.9 or $\geq 2.0$ units/day), type of job (sedentary, moderate or hard), leisure-time physical activity (0, 1-15.9 or $\geq 16$ MET-hours/week) and parental history of colorectal cancer.

Gene-gene and gene-environment (smoking) interactions were statistically evaluated based on the likelihood test, comparing the model including a term or terms for interaction and the model without. Deviation from the Hardy-Weinberg equilibrium was evaluated by chisquare test with 1 degree of freedom. Statistical significance was declared if a two-sided $P$-value was less than 0.05 . Statistical analyses were carried out using SAS version 9.2 (SAS Institute, Cary, NC). 


\section{Results}

Table 1 shows the association between cigarette smoking and colorectal cancer risk. Adjustment for the covariates did not markedly change the results. As compared with lifelong nonsmokers, men and women with a light exposure to cigarette smoking (1-399 cigarette-years) showed a moderate decrease in the OR of colorectal cancer. The decreases in the OR in both sexes combined and in women were statistically significant. The ORs for higher categories of smoking were slightly greater than unity in both men and women, but the increases were not statistically significant. In men and women combined, the multivariate-adjusted ORs for past and current smokers as compared with lifelong nonsmokers were 0.90 (95\% CI 0.66-1.24) and 0.80 (95\% CI 0.58-1.05), respectively. There was no clear association between cumulative years of smoking and colorectal cancer; the multivariateadjusted ORs for $0,1-14,15-29$ and $\geq 30$ years of smoking were 1.00 (referent), 0.73 (0.51-1.05), 0.92 (0.65-1.29) and 1.02 (0.69-1.49), respectively. Cases of colon and rectal cancer numbered 384 and 290, respectively; 11 cases had both colon and rectal cancers. The multivariate-adjusted ORs of colon cancer for 0, 1-399, 400-799 and 800 cigarette-years were 1.00 (referent), 0.49 (95\% CI 0.32-0.73), $0.89(0.60-1.33)$ and $1.02(0.62-1.69)$, respectively, while the corresponding values for rectal cancer were 1.00 (referent), 0.92 (0.60-1.42), $1.72(1.10-2.66)$ and 1.23 (0.66$2.26)$, respectively. The OR of rectal cancer for the highest two categories combined was 1.60 (95\% CI 1.04-2.45).
None of the five polymorphisms showed a measurable association with the risk of colorectal cancer, nor did the composite genotype of GSTM1 and GSTT1 (Table 2). Each polymorphism was not associated with smoking history (cigarette-years) in either men or women among controls (data not shown). Frequencies of $C Y P 1 A 1 * 2 A$ allele were 0.363 in cases and 0.372 in controls, and frequencies of $C Y P 1 A 1 * 2 C$ allele were 0.221 in cases and 0.230 in controls. Frequencies of the 187Ser allele of NQO1 polymorphism were 0.376 in cases and 0.385 in controls. Genotype distributions of these three polymorphisms were in accordance with the Hardy-Weinberg equilibrium within each cases and controls (all $P>0.05$ ). $C Y P 1 A 1 * 2 A$ and $C Y P 1 A 1 * 2 C$ polymorphisms were in complete linkage disequilibrium.

There was no material interaction between cigarette smoking and each polymorphism on colorectal cancer risk (Table 3). Repeated analyses for men and for colon and rectal cancers did not show any measurable interaction between smoking and genotype.

We further examined gene-gene interactions for the combination of CYP1A1 and GST polymorphisms (Table 4) and $C Y P 1 A 1$ and $N Q O 1$ polymorphisms (Table 5). The combination of $C Y P 1 A 1 * 2 A$ or $C Y P 1 A 1 * 2 C$ and GSTT1 polymorphisms showed a nearly statistically significant or significant interaction. The composite genotype of GSTT1 non-null and $C Y P 1 A 1 * 2 A$ or $C Y P 1 A 1 * 2 C$ allele was associated with a decreased risk of colorectal cancer (Table 4). There was no measurable interaction between

Table 1: Risk of colorectal cancer according to cigarette smoking

\begin{tabular}{|c|c|c|c|c|}
\hline \multirow[b]{2}{*}{ Cigarette-years } & \multicolumn{2}{|c|}{ Number (\%) } & \multirow[b]{2}{*}{ OR $(95 \% \mathrm{CI}) *$} & \multirow[b]{2}{*}{ OR $(95 \% \mathrm{CI})^{\dagger}$} \\
\hline & Cases & Controls & & \\
\hline \multicolumn{5}{|l|}{ Both sexes } \\
\hline 0 & 299 (43.6) & 326 (41.9) & 1.00 (referent) & 1.00 (referent) \\
\hline $1-399$ & $117(17.1)$ & $201(25.8)$ & $0.68(0.50-0.94)$ & $0.65(0.47-0.89)$ \\
\hline $400-799$ & $195(28.5)$ & $180(23.1)$ & $1.21(0.88-1.68)$ & $1.16(0.83-1.62)$ \\
\hline$\geq 800$ & $74(10.8)$ & $71(9.1)$ & $1.21(0.79-1.86)$ & $1.14(0.73-1.77)$ \\
\hline \multicolumn{5}{|l|}{ Men } \\
\hline 0 & $80(18.8)$ & $92(18.8)$ & 1.00 (referent) & 1.00 (referent) \\
\hline $1-399$ & $94(22.1)$ & $158(32.2)$ & $0.73(0.49-1.09)$ & $0.69(0.46-1.04)$ \\
\hline $400-799$ & $182(42.7)$ & $171(34.9)$ & $1.24(0.85-1.81)$ & $1.15(0.78-1.71)$ \\
\hline$\geq 800$ & $70(16.4)$ & $69(14.1)$ & $1.16(0.72-1.87)$ & $1.05(0.64-1.71)$ \\
\hline \multicolumn{5}{|l|}{ Women } \\
\hline 0 & $219(84.6)$ & $234(81.3)$ & 1.00 (referent) & 1.00 (referent) \\
\hline $1-399$ & $23(8.9)$ & $43(14.9)$ & $0.55(0.32-0.95)$ & $0.48(0.27-0.86)$ \\
\hline$\geq 400$ & $17(6.6)$ & $11(3.8)$ & $1.59(0.72-3.51)$ & $1.54(0.67-3.55)$ \\
\hline
\end{tabular}

* Adjusted for sex, age, and residence area.

† Adjusted for sex, age, residence area, alcohol consumption, body mass index, type of job, leisure-time physical activity and parental colorectal cancer. 
Table 2: Risk of colorectal cancer in relation to selected genetic polymorphisms

\begin{tabular}{|c|c|c|c|}
\hline \multirow[b]{2}{*}{ Genotype } & \multicolumn{2}{|c|}{ Number (\%) } & \multirow[b]{2}{*}{ OR $(95 \% \mathrm{CI}) *$} \\
\hline & Cases, $\mathrm{n}=685$ & Controls, $n=778$ & \\
\hline \multicolumn{4}{|l|}{$C Y P 1 A 1 * 2 A$} \\
\hline $0+$ & $283(41.3)$ & $305(39.2)$ & 1.00 (referent) \\
\hline 1 & $307(44.8)$ & $368(47.3)$ & $0.90(0.72-1.13)$ \\
\hline 2 & 95 (13.9) & $105(13.5)$ & $0.97(0.70-1.35)$ \\
\hline \multicolumn{4}{|l|}{$C Y P 1 A 1 * 2 C$} \\
\hline $0+$ & $418(61.0)$ & $461(59.3)$ & 1.00 (referent) \\
\hline 1 & $231(33.7)$ & $276(35.5)$ & $0.94(0.75-1.17)$ \\
\hline 2 & $36(5.3)$ & $41(5.3)$ & $1.00(0.62-1.62)$ \\
\hline \multicolumn{4}{|l|}{ GSTM1 } \\
\hline Non-null & $328(47.9)$ & $356(45.8)$ & 1.00 (referent) \\
\hline Null & $357(52.1)$ & $422(54.2)$ & $0.90(0.73-1.11)$ \\
\hline \multicolumn{4}{|l|}{ GSTT1 } \\
\hline Non-null & $347(50.7)$ & $435(55.9)$ & 1.00 (referent) \\
\hline Null & $338(49.3)$ & $343(44.1)$ & $1.20(0.97-1.48)$ \\
\hline \multicolumn{4}{|l|}{ GSTM1 + GSTT1 } \\
\hline Non-null & $502(73.3)$ & $589(75.7)$ & 1.00 (referent) \\
\hline Null & $183(26.7)$ & $189(24.3)$ & $1.09(0.86-1.39)$ \\
\hline \multicolumn{4}{|c|}{ NQ01 Pro187Ser‡ } \\
\hline Pro/Pro & $259(37.9)$ & $282(36.3)$ & 1.00 (referent) \\
\hline Pro/Ser & $336(49.1)$ & $392(50.5)$ & $0.94(0.75-1.18)$ \\
\hline Ser/Ser & $89(13.0)$ & $103(13.3)$ & $0.97(0.69-1.35)$ \\
\hline
\end{tabular}

* Adjusted for sex, age, residence area, cigarette smoking, alcohol consumption, body mass index, type of job, leisure-time physical activity and parental colorectal cancer.

† Number of the variant allele.

‡ One case and one control were excluded because of undetermined genotype.

CYP1A1 and NQO1 polymorphisms in relation to colorectal cancer risk (Table 5). Decreased risks for the combination of CYP1A1 variant allele and GSTT1 non-null genotype were observed only in men; the multivariateadjusted ORs were 0.62 (95\% CI 0.42-0.90) for the combination of CYP1A1*2A allele and GSTT1 non-null genotype $\left(P_{\text {interaction }}=0.04\right)$ and $0.63(95 \%$ CI $0.43-0.91)$ for that of CYP1A1*2C allele and GSTT1 non-null genotype $\left(P_{\text {interaction }}=0.07\right)$.

Cigarette smoking showed no effect modification on associations with composite genotypes of CYP1A1 and GST or NQO1 polymorphisms. For example, the decreased risk among individuals harboring CYP1A1*2A or CYP1A1*2C allele and GSTT1 non-null genotype was observed regardless of exposure to smoking. In other words, high exposure to smoking was consistently related to an increased risk of colorectal cancer across different composite genotypes (see additional file 1).

\section{Discussion}

Many studies have addressed the association between cigarette smoking and colorectal cancer risk, and their findings are highly variable although an $18 \%$ increase in colorectal cancer risk was estimated for ever-smokers versus never-smokers in a recent meta-analysis [7]. The variable results may be due to differences in study method, statistical power and ethnicity. The association may differ by sex or location of colorectal cancer. In fact, prospective studies showed higher risk estimates than case-control studies in the meta-analysis [7]. Furthermore, while an increased risk associated with smoking was observed in both men and women, the positive association with smoking was more evident for rectal cancer than for colon cancer [7]. The present finding adds to evidence that cigarette smoking is associated with increased risk of rectal cancer. It was unexpected that individuals with an exposure of 1-399 cigarette-years had a decreased risk of colorectal cancer. This decrease was observed for 
Table 3: Effect modification of cigarette smoking on colorectal cancer risk associated with selected genetic polymorphisms

\begin{tabular}{|c|c|c|c|c|c|}
\hline \multirow[b]{2}{*}{ Genotype } & \multicolumn{2}{|c|}{$<400$} & \multicolumn{2}{|c|}{$\geq 400$} & \multirow[b]{2}{*}{$P$ for interaction } \\
\hline & $n^{*}$ & OR $(95 \% \mathrm{Cl}) \dagger$ & $\mathbf{n}^{*}$ & OR (95\% Cl)† & \\
\hline \multicolumn{6}{|l|}{$C Y P 1 A 1 * 2 A$} \\
\hline $0 \neq$ & $161 / 207$ & 1.00 (referent) & $122 / 98$ & $1.76(1.19-2.59)$ & 0.14 \\
\hline \multicolumn{6}{|l|}{$C Y P 1 A 1 * 2 C$} \\
\hline $0 \neq$ & $243 / 309$ & 1.00 (referent) & $175 / 152$ & $1.58(1.14-2.20)$ & 0.30 \\
\hline$\geq 1$ & $173 / 218$ & $1.03(0.79-1.34)$ & $94 / 99$ & $1.28(0.87-1.86)$ & \\
\hline \multicolumn{6}{|l|}{ GSTM1 } \\
\hline Non-null & $207 / 245$ & 1.00 (referent) & $121 / 111$ & $1.38(0.96-1.97)$ & 0.68 \\
\hline Null & $209 / 282$ & $0.88(0.67-1.14)$ & $148 / 140$ & $1.33(0.94-1.87)$ & \\
\hline \multicolumn{6}{|l|}{ GSTT1 } \\
\hline Non-null & $211 / 301$ & 1.00 (referent) & $136 / 134$ & $1.51(1.08-2.13)$ & 0.60 \\
\hline Null & $205 / 226$ & $1.24(0.95-1.61)$ & $133 / 117$ & $1.67(1.18-2.37)$ & \\
\hline \multicolumn{6}{|l|}{ GSTM1+GSTT1 } \\
\hline Non-null & $304 / 407$ & 1.00 (referent) & $198 / 182$ & $1.53(1.14-2.07)$ & 0.29 \\
\hline Null & $112 / 120$ & $1.20(0.89-1.63)$ & $71 / 69$ & $1.41(0.94-2.11)$ & \\
\hline \multicolumn{6}{|l|}{ NQ01 Pro187Ser§ } \\
\hline Pro/Pro & $157 / 189$ & 1.00 (referent) & $102 / 93$ & $1.41(0.95-2.09)$ & 0.89 \\
\hline $\begin{array}{l}\text { Pro/Ser + Ser/ } \\
\text { Ser }\end{array}$ & $259 / 338$ & $0.94(0.72-1.24)$ & $166 / 157$ & $1.37(0.96-1.94)$ & \\
\hline
\end{tabular}

\footnotetext{
* Numbers of cases/controls.

† Adjusted for sex, age, residence area, alcohol consumption, body mass index, type of job, leisure-time physical activity and parental colorectal cancer.

₹ Number of the variant allele.

$\S$ One case and one control were excluded because of undetermined genotype.
}

colon cancer but not for rectal cancer, and was more marked in women. Previously, some case-control studies also suggested that smoking was associated with a decreased risk of distal colon cancer in Caucasians [40] and of colon cancer in Japanese [41,42]. We have no clear explanation to the decreased risk of colon cancer associated with light smoking although confounding remains a possible explanation.

In agreement with the results from three studies [1820], the present study did not show an association of either CYP1A1*2A or CYP1A1*2C polymorphism with colorectal cancer risk. An 8-fold increased risk of colorectal cancer among Japanese homozygotes of $C Y P 1 A 1 * 2 A$ allele in Hawaii is probably a chance finding due to small numbers (23 cases and 59 controls) [17]. Of these previous studies, two examined the interaction between CYP1A1 polymorphisms and smoking [19,20]. One study reported an increased risk of rectal cancer, but not of colon cancer, among former and current smokers who did not carry either $C Y P 1 A 1 * 2 A$ or $C Y P 1 A 1 * 2 C$ allele [19], while the other study showed no interaction between either of the CYP1A1 polymorphisms and smoking on colorectal cancer risk [20].

The GSTM1 and GSTT1 polymorphisms were unrelated to colorectal cancer risk singly or in combination in the present study. GSTM1 null genotype was associated with a small, statistically significant increase in the risk of colorectal cancer in some case-control studies [21,32], but not in several other studies [20,28-31]. Likewise, the previous findings on GSTT1 null genotype and colorectal cancer are inconsistent. A meta-analysis based on 11 studies reported a small increase in colorectal cancer risk associated with GSTT1 null genotype, but the results of these studies were highly heterogeneous [24]. Most of the previous studies found no increase in the risk of colorectal cancer in individuals with the combined null genotype of GSTM1 and GSTT1 $[21,28,31]$. On the other hand, a 5fold increased risk of colorectal cancer was reported for simultaneous carriers of both GSTM1 and GSTT1 null genotypes in a study of 144 cases and 329 healthy con- 
Table 4: Combinations of CYP1A1 and GST polymorphisms and colorectal cancer risk

\begin{tabular}{|c|c|c|c|c|c|}
\hline \multirow[b]{2}{*}{ Combination of genotypes } & & \multicolumn{2}{|c|}{ Number (\%) } & \multirow[b]{2}{*}{ OR $(95 \% \mathrm{Cl}) *$} & \multirow[b]{2}{*}{$\begin{array}{c}P \text { for } \\
\text { interaction }\end{array}$} \\
\hline & & Cases & Controls & & \\
\hline$C Y P 1 A 1 * 2 A$ & GSTM1 & & & & \\
\hline $0 \dagger$ & Non-null & $122(17.8)$ & $135(17.4)$ & 1.00 (referent) & \\
\hline$\geq 1$ & Non-null & $206(30.1)$ & $221(28.4)$ & $1.02(0.74-1.40)$ & 0.34 \\
\hline 0 & Null & $161(23.5)$ & $170(21.9)$ & $1.01(0.72-1.42)$ & \\
\hline$\geq 1$ & Null & $196(28.6)$ & $252(32.4)$ & $0.84(0.61-1.15)$ & \\
\hline$C Y P 1 A 1 * 2 A$ & GSTT1 & & & & \\
\hline $0+$ & Non-null & $147(21.5)$ & $158(20.3)$ & 1.00 (referent) & \\
\hline$\geq 1$ & Non-null & $200(29.2)$ & $277(35.6)$ & $0.75(0.56-1.01)$ & 0.06 \\
\hline 0 & Null & $136(19.9)$ & $147(18.9)$ & $0.93(0.67-1.30)$ & \\
\hline$\geq 1$ & Null & $202(29.5)$ & $196(25.2)$ & $1.07(0.79-1.45)$ & \\
\hline$C Y P 1 A 1 * 2 A$ & GSTT1 + GSTM1 & & & & \\
\hline $0 \dagger$ & Non-null & $203(29.6)$ & $222(28.5)$ & 1.00 (referent) & \\
\hline$\geq 1$ & Non-null & $299(43.6)$ & $367(47.2)$ & $0.88(0.69-1.13)$ & 0.51 \\
\hline 0 & Null & $80(11.7)$ & $83(10.7)$ & $0.99(0.68-1.43)$ & \\
\hline$\geq 1$ & Null & $103(15.0)$ & $106(13.6)$ & $1.03(0.73-1.44)$ & \\
\hline$C Y P 1 A 1 * 2 C$ & GSTM1 & & & & \\
\hline $0+$ & Non-null & $187(27.3)$ & $207(26.6)$ & 1.00 (referent) & \\
\hline$\geq 1$ & Non-null & $141(20.6)$ & $149(19.2)$ & $1.06(0.78-1.45)$ & 0.29 \\
\hline 0 & Null & $231(33.7)$ & $254(32.6)$ & $0.98(0.75-1.29)$ & \\
\hline$\geq 1$ & Null & $126(18.4)$ & $168(21.6)$ & $0.83(0.60-1.13)$ & \\
\hline$C Y P 1 A 1 * 2 C$ & GSTT1 & & & & \\
\hline $0+$ & Non-null & $214(31.2)$ & $239(30.7)$ & 1.00 (referent) & \\
\hline$\geq 1$ & Non-null & $133(19.4)$ & $196(25.2)$ & $0.76(0.56-1.01)$ & 0.02 \\
\hline 0 & Null & $204(29.8)$ & $222(28.5)$ & $0.98(0.75-1.29)$ & \\
\hline$\geq 1$ & Null & 134 (19.6) & $121(15.6)$ & $1.23(0.90-1.69)$ & \\
\hline$C Y P 1 A 1 * 2 C$ & GSTT1 + GSTM1 & & & & \\
\hline $0+$ & Non-null & $300(43.8)$ & $337(43.3)$ & 1.00 (referent) & \\
\hline$\geq 1$ & Non-null & $202(29.5)$ & $252(32.4)$ & $0.90(0.70-1.15)$ & 0.39 \\
\hline 0 & Null & $118(17.2)$ & $124(15.9)$ & $1.00(0.74-1.36)$ & \\
\hline$\geq 1$ & Null & $65(9.5)$ & $65(8.4)$ & $1.13(0.77-1.66)$ & \\
\hline
\end{tabular}

* Adjusted for sex, age, residence area, cigarette smoking, alcohol consumption, body mass index, type of job, leisure-time physical activity and parental colorectal cancer.

† Number of the variant allele.

trols in Spain [43]. In that study [43], GSTM1 and GSTT1 null genotypes were also statistically significantly associated with 1.9-fold and 3.6-fold increased risks, respectively. Frequencies of GSTM1 and GSTT1 null genotypes vary with different populations [22], but the difference in genotype distribution does not seem to explain the different results. The combined null genotype of GSTM1 and GSTT1 accounted for $24 \%$ among controls in the present study and for 7\% in the Spanish study [43]. The statistical power was obviously greater in the present study than in the Spanish study.

At least six case-control studies have examined the relation between NQO1 Pro187Ser polymorphism and colorectal cancer [27], and only one study, which included 371 cases and 415 healthy controls in the Netherlands, showed a statistically significant increase in the risk associated with the variant 187 Ser allele [44]. On the other hand, homozygotes of the NQO1 187Ser allele was 
Table 5: Combinations of CYP1A1 and NQO1 polymorphisms and colorectal cancer risk

\begin{tabular}{|c|c|c|c|c|c|}
\hline \multirow[b]{2}{*}{ Combination of genotypes } & & \multicolumn{2}{|c|}{ Number (\%) } & \multirow[b]{2}{*}{ OR $(95 \% \mathrm{CI})^{*}$} & \multirow[b]{2}{*}{$\begin{array}{c}P \text { for } \\
\text { interaction }\end{array}$} \\
\hline & & Cases & Controls & & \\
\hline CYP1A1*2A & NQ01 Pro187Ser† & & & & \\
\hline $0 \neq$ & Pro/Pro & $126(18.4)$ & $118(15.2)$ & 1.00 (referent) & \\
\hline 0 & Pro/Ser + Ser/Ser & $157(23.0)$ & $187(24.1)$ & $0.81(0.58-1.14)$ & \\
\hline$\geq 1$ & Pro/Ser + Ser/Ser & $268(39.2)$ & $308(39.6)$ & $0.83(0.61-1.13)$ & \\
\hline $\mathrm{CYP} 1 \mathrm{~A} 1 * 2 \mathrm{C}$ & NQ01 Pro187Sert & & & & \\
\hline $0 \neq$ & Pro/Pro & $162(23.7)$ & $176(22.7)$ & 1.00 (referent) & \\
\hline$\geq 1$ & Pro/Pro & $97(14.2)$ & $106(23.6)$ & $1.04(0.73-1.48)$ & 0.53 \\
\hline$\geq 1$ & Pro/Ser + Ser/Ser & $169(24.7)$ & $210(27.0)$ & $0.90(0.67-1.22)$ & \\
\hline
\end{tabular}

* Adjusted for sex, age, residence area, cigarette smoking, alcohol consumption, body mass index, type of job, leisure-time physical activity and parental colorectal cancer.

† One case and one control were excluded because of undetermined genotype.

$\neq$ Number of the variant allele.

associated with a 2-fold increase in the prevalence odds of colorectal adenomas in the United States [34]. In that study [34], individuals having both $C Y P 1 A 1 * 2 C$ and NQO1 187Ser variant alleles showed a significantly increased risk, particularly among heavy smokers. The present findings showed neither an increased risk of colorectal cancer in relation to the composite of CYP1A1 variant allele and NQO1 187Ser alleles nor an interaction between the composite genotypes and smoking.

A unique finding in the present study is that $C Y P 1 A 1 * 2 A$ or $C Y P 1 A 1 * 2 C$ allele was associated with a decreased risk only in individuals with GSTT1 non-null genotype. Interpretation of these findings is rather difficult, particularly because the association was confined to men. Available evidence suggests at least a secondary role of the CYP1A1 polymorphisms for increased risks of smoking-related cancers although the association between these polymorphisms and enzyme activity or property remains controversial [16]. Two case-controls studies of smaller sizes previously examined the combined effect of $C Y P 1 A 1 * 2 C$ and either GSTM1 [20,21] or GSTT1 [20] null genotype, showing no interaction between the two. The present findings on $C Y P 1 A 1$ and GSTT1 polymorphisms in combination may be due to chance, and need to be consolidated in further studies.

The use of community controls, the large number of subjects, and ethnic homogeneity of the study population were strengths of the present study. The statistical powers were fairly large except for $C Y P 1 A 1 * 2 C$ polymorphism. The powers of detecting an OR of 1.5 for variant homozygotes compared with wild homozygotes (two-sided $\alpha=$ $0.05)$ were 0.71 for $C Y P 1 A 1 * 2 A, 0.42$ for $C Y P 1 A 1 * 2 C$ and 0.69 for NQO1, and the corresponding values for null ver- sus non-null genotype were 0.96 for GSTM1 and 0.93 for GSTT1. There were several limitations to be discussed. The participation in the interview was not as high in the controls (60\%) as in the cases (80\%). We had no information as to the difference between participant and nonparticipant controls with respect to smoking history. The overall participation for genotyping was rather low (65\% in cases and 56\% in controls). Although older persons and women were less likely to give consent for the genotyping, there was no difference between those who gave consent and those who did not in terms of smoking, residence area, and alcohol use [45]. A retrospective assessment of cumulative exposure to cigarette smoking is subject to inaccuracy, and may have been biased because interviewers had known case-control status. Lifestyle factors were assessed for different time periods in the past for ease of recalling. This may have caused inaccuracy to different extents for the covariates, leaving different magnitudes of residual confounding. It is known that GSTM1 and GSTT1 genes contain nonsynonymous SNPs which may modify the enzyme activity [46], but these SNPs seem to be of little relevance in Asians as well as Caucasians [47]. Finally, although cases with familial adenomatous polyposis were not included, other hereditary colorectal cancers were not specifically ascertained in the present study. However, in the analysis excluding 16 cases and 40 controls aged $<40$ years, the results were essentially the same as those described above.

\section{Conclusions}

The present study showed a moderately decreased risk of colorectal cancer, especially of colon cancer, in individuals with a light exposure to cigarette-smoking. A high 
exposure to cigarette smoking was associated with an increased risk of rectal cancer. None of the genetic polymorphisms relevant to the metabolism of tobacco carcinogens showed a measurable association with the risk of colorectal cancer. The observed interactions between CYP1A1 and GSTT1 polymorphisms warrant further investigation.

\section{Additional material}

\section{Additional file 1 Supplemental Table. Effect modification of cigarette} smoking on colorectal cancer risk associated with combinations of CYP1A1 and GST or NQO1 polymorphisms.

\section{Abbreviations}

Cl: confidence interval; CYP: cytochrome P-450; GST: gluthathione S-transferase; NQO1: NAD(P)H:quinone oxidoreductase 1; OR: odds ratio; $\mathrm{PAH}$ : polycyclic aromatic hydrocarbon; PCR-RFLP: polymerase chain reaction-restriction fragment length polymorphism.

\section{Competing interests}

The authors declare that they have no competing interests.

\section{Authors' contributions}

HN performed data analysis and prepared the draft. SK was in charge of the whole process including preparation of the manuscript. GY was in charge of DNA preparation and storage and analyzed data. KT and JN designed the study and conducted the survey. RM, MT, YK, YM, TO, KI, KF, TM, YY, KT, HI and RT contributed to study design and implementation of the survey. All authors read and approved the final manuscript.

\section{Acknowledgements}

This work was supported by a Grant-in-Aid for Scientific Research on Priority Areas from the Ministry of Education, Culture, Sports and Technology, Japan (1814022). The computation was mainly carried out using the computer facilities at Research Institute for Information Technology, Kyushu University. The authors acknowledge support from Emeritus Professors Keizo Sugimachi, Seiyo Ikeda, Takayuki Shirakusa, and Sumitaka Arima; and Drs. Motonori Saku, Yoichi Ikeda, Soichiro Maekawa, Kazuo Tanoue, Kinjiro Sumiyoshi, and Shoichiro Saito in conducting the survey of cases. The following physicians kindly supervised the survey of the controls at their clinics: Drs. Hideaki Baba, Tomonori Endo, Hiroshi Hara, Yoichiro Hirokata, Motohisa Ikeda, Masayoshi Ishibashi, Fumiaki Itoh, Yasuhiro Iwanaga, Hideki Kaku, Shoshi Kaku, Minori Kanazawa, Akira Kobayashi, Ryunosuke Kumashiro, Shinichi Matsumoto, Soukei Mioka, Umeji Miyakoda, Osamu Nakagaki, Nobuyoshi Nogawa, Nobuyoki Ogami, Toyoaki Okabayashi, Hironao Okabe, Nishiku Saku, Masafumi Tanaka, Masahiro Ueda, Bunichi Ushio, and KoheishoYasunaga. The authors are grateful to Ms. Hiroko Mizuta, Ms. Masumi Koga, and Ms. Kumiko Arie for their assistance.

\section{Author Details}

1Department of Preventive Medicine, Graduate School of Medical Sciences, Kyushu University, 3-1-1 Maidashi, Higashi-ku, Fukuoka, 812-8582, Japan, 2Department of Surgery and Oncology, Graduate School of Medical Sciences, Kyushu University, 3-1-1 Maidashi, Higashi-ku, Fukuoka, 812-8582, Japan, ${ }^{3}$ Department of Surgery and Science, Graduate School of Medical Sciences, Kyushu University, 3-1-1 Maidashi, Higashi-ku, Fukuoka, 812-8582, Japan, ${ }^{4}$ Department of Gastroenterological Surgery, National Kyushu Cancer Center, 3-1-1 Notame, Minami-ku, Fukuoka, 811-1395, Japan, 5 Division of Surgery, National Kyushu Medical Center, 1-8-1 Jigyohama, Chuo-ku, Fukuoka, 8108563, Japan, ${ }^{2}$ Department of Surgery, Fukuoka University Chikushi Hospital, 377-1 Oaza-zokumyoin, Chikushino-shi, 818-0067, Japan, 7 Department of Regenerative Medicine and Transplantation, Faculty of Medicine, Fukuoka University, 7-45-1 Nanakuma, Jonan-ku, Fukuoka, 814-0180, Japan, 8Division of Surgery, Fukuoka City Hospital, School of Medicine, 13-1 Yoshizuka-honmachi, Hakata-ku, Fukuoka, 812-0046, Japan, 9 Division of Surgery, Hamanomachi General Hospital, 3-5-27 Maizuru, Chuo-ku, Fukuoka, 810-8539, Japan and 10Division of Surgery, Fukuoka Red Cross Hospital, 3-1-1 Ogusu, Minami-ku, Fukuoka, 815-8555, Japan
Received: 1 September 2009 Accepted: 10 June 2010

Published: 10 June 2010

\section{References}

1. de la Chapelle A: Genetic predisposition to colorectal cancer. Nat Rev Cancer 2004, 4:769-780

2. Lichtenstein P, Holm NV, Verkasalo PK, Iliadou A, Kaprio J, Koskenvuo M, Pukkala E, Skytthe A, Hemminki K: Environmental and heritable factors in the causation of cancer--analyses of cohorts of twins from Sweden Denmark, and Finland. N Engl J Med 2000, 343:78-85.

3. Tomlinson IP, Webb E, Carvajal-Carmona L, Broderick P, Howarth K, Pittman AM, Spain S, Lubbe S, Walther A, Sullivan K, Jaeger E, Fielding S, Rowan A, Vijayakrishnan J, Domingo E, Chandler I, Kemp Z, Qureshi M, Farrington SM, Tenesa A, Prendergast JG, Barnetson RA, Penegar S, Barclay E, Wood W, Martin L, Gorman M, Thomas H, Peto J, Bishop DT, Gray R, Maher ER, Lucassen A, Kerr D, Evans DG, CORGI Consortium, Schafmayer C, Buch S, Völzke H, Hampe J, Schreiber S, John U, Koessler T, Pharoah P, van Wezel T, Morreau H, Wijnen JT, Hopper JL, Southey MC, Giles GG, Severi G, Castellví-Bel S, Ruiz-Ponte C, Carracedo A, Castells A, EPICOLON Consortium, Försti A, Hemminki K, Vodicka P, Naccarati A, Lipton L, Ho JW, Cheng KK, Sham PC, Luk J, Agúndez JA, Ladero JM, de la Hoya M, Caldés T, Niittymäki I, Tuupanen S, Karhu A, Aaltonen L, Cazier JB, Campbell H, Dunlop MG, Houlston RS: A genome-wide association study identifies colorectal cancer susceptibility loci on chromosomes 10p14 and 8q23.3. Nat Genet 2008, 40:623-630.

4. Pittman AM, Webb E, Carvajal-Carmona L, Howarth K, Di Bernardo MC, Broderick P, Spain S, Walther A, Price A, Sullivan K, Twiss P, Fielding S, Rowan A, Jaeger E, Vijayakrishnan J, Chandler I, Penegar S, Qureshi M, Lubbe S, Domingo E, Kemp Z, Barclay E, Wood W, Martin L, Gorman M, Thomas H, Peto J, Bishop T, Gray R, Maher ER, Lucassen A, Kerr D, Evans GR, CORGI Consortium, van Wezel T, Morreau H, Wijnen JT, Hopper JL, Southey MC, Giles GG, Severi G, Castellví-Bel S, Ruiz-Ponte C, Carracedo A, Castells A, EPICOLON Consortium, Försti A, Hemminki K, Vodicka P, Naccarati A, Lipton L, Ho JW, Cheng KK, Sham PC, Luk J, Agúndez JA, Ladero JM, de la Hoya M, Caldés T, Niittymäki I, Tuupanen S, Karhu A, Aaltonen LA, Cazier JB, Tomlinson IP, Houlston RS: Refinement of the basis and impact of common 11q23.1 variation to the risk of developing colorectal cancer. Hum Mol Genet 2008, 17:3720-3727.

5. Giovannucci $E$ : An updated review of the epidemiological evidence that cigarette smoking increases risk of colorectal cancer. Cancer Epidemiol Biomarkers Prev 2001, 10:725-731.

6. Botteri E, lodice S, Raimondi S, Maisonneuve P, Lowenfels AB: Cigarette smoking and adenomatous polyps: a meta-analysis. Gastroenterology 2008, 134:388-395.

7. Botteri E, lodice S, Bagnardi V, Raimondi S, Lowenfels AB, Maisonneuve P: Smoking and colorectal cancer: a meta-analysis. JAMA 2008, 300:2765-2778.

8. Heineman EF, Zahm SH, McLaughlin JK, Vaught JB: Increased risk of colorectal cancer among smokers: results of a 26-year follow-up of US veterans and a review. Int J Cancer 1994, 59:728-738.

9. Giovannucci E, Rimm EB, Stampfer MJ, Colditz GA, Ascherio A, Kearney J, Willett WC: A prospective study of cigarette smoking and risk of colorectal adenoma and colorectal cancer in U.S. men. J Nat/ Cancer Inst 1994, 86:183-191.

10. Giovannucci E, Colditz GA, Stampfer MJ, Hunter D, Rosner BA, Willett WC, Speizer FE: A prospective study of cigarette smoking and risk of colorectal adenoma and colorectal cancer in U.S. women. J Nat/ Cancer Inst 1994, 86:192-199.

11. Paskett ED, Reeves KW, Rohan TE, Allison MA, Williams CD, Messina CR, Whitlock E, Sato A, Hunt JR: Association between cigarette smoking and colorectal cancer in the Women's Health Initiative. J Natl Cancer Inst 2007, 99:1729-1735.

12. Terry PD, Miller AB, Rohan TE: Prospective cohort study of cigarette smoking and colorectal cancer risk in women. Int J Cancer 2002, 99:480-483.

13. Nyrén $O$, Bergström $R$, Nyström $L$, Engholm G, Ekbom A, Adami HO, Knutsson A, Stjernberg N: Smoking and colorectal cancer: a 20-year follow-up study of Swedish construction workers. J Nat/ Cancer Inst 1996, 88:1302-1307.

14. D'Avanzo B, La Vecchia C, Franceschi S, Gallotti L, Talamini R: Cigarette smoking and colorectal cancer: a study of 1,584 cases and 2,879 controls. Prev Med 1995, 24:571-579. 
15. Bartsch H, Nair U, Risch A, Rojas M, Wikman H, Alexandrov K: Genetic polymorphism of CYP genes, alone or in combination, as a risk modifier of tobacco-related cancers. Cancer Epidemiol Biomarkers Prev 2000, 9:3-28.

16. Agúndez JA: Cytochrome P450 gene polymorphism and cancer. Curr Drug Metab 2004, 5:211-224.

17. Sivaraman L, Leatham MP, Yee J, Wilkens LR, Lau AF, Le Marchand L: CYP1A1 genetic polymorphisms and in situ colorectal cancer. Cancer Res 1994, 54:3692-3695.

18. Ishibe N, Stampfer M, Hunter DJ, Hennekens C, Kelsey KT: A prospective study of cytochrome P450 1A1 polymorphisms and colorectal cancer risk in men. Cancer Epidemiol Biomarkers Prev 2000, 9:855-856.

19. Slattery ML, Samowtiz W, Ma K, Murtaugh M, Sweeney C, Levin TR, Neuhausen S: CYP1A1, cigarette smoking, and colon and rectal cancer. Am J Epidemiol 2004, 160:842-852.

20. Little J, Sharp L, Masson LF, Brockton NT, Cotton SC, Haites NE, Cassidy J: Colorectal cancer and genetic polymorphisms of CYP1A1, GSTM1 and GSTT1: a case-control study in the Grampian region of Scotland. Int J Cancer 2006, 119:2155-2164

21. Sachse C, Smith G, Wilkie MJ, Barrett JH, Waxman R, Sullivan F, Forman D, Bishop DT, Wolf CR: A pharmacogenetic study to investigate the role of dietary carcinogens in the etiology of colorectal cancer. Carcinogenesis 2002, 23:1839-1849.

22. Strange RC, Fryer AA: The glutathione S-transferases: influence of polymorphism on cancer susceptibility. IARC Sci Pub/ 1999, 148:231-249.

23. Cotton SC, Sharp L, Little J, Brockton N: Glutathione S-transferase polymorphisms and colorectal cancer: a HuGE review. Am J Epidemiol 2000, 151:7-32.

24. Chen K, Jiang QT, He HQ: Relationship between metabolic enzyme polymorphism and colorectal cancer. World J Gastroenterol 2005, 11:331-335

25. Cote ML, Chen W, Smith DW, Benhamou S, Bouchardy C, Butkiewicz D, Fong KM, Gené M, Hirvonen A, Kiyohara C, Larsen JE, Lin P, RaaschouNielsen O, Povey AC, Reszka E, Risch A, Schneider J, Schwartz AG, Sorensen M, To-Figueras J, Tokudome S, Pu Y, Yang P, Wenzlaff AS, Wikman H, Taioli E: Meta- and pooled analysis of GSTP1 polymorphism and lung cancer: a HuGE-GSEC review. Am J Epidemiol 2009, 169:802-814.

26. Nebert DW, Roe AL, Vandale SE, Bingham E, Oakley GG: NAD(P)H:quinone oxidoreductase (NQO1) polymorphism, exposure to benzene, and predisposition to disease: a HuGE review. Genet Med 2002, 4:62-70.

27. Chao C, Zhang ZF, Berthiller J, Boffetta P, Hashibe M: NAD(P)H:quinone oxidoreductase 1 (NQO1) Pro187Ser polymorphism and the risk of lung, bladder, and colorectal cancers: a meta-analysis. Cancer Epidemiol Biomarkers Prev 2006, 15:979-987.

28. Huang K, Sandler RS, Millikan RC, Schroeder JC, North KE, Hu J: GSTM1 and GSTT1 polymorphisms, cigarette smoking, and risk of colon cancer: a population-based case-control study in North Carolina (United States). Cancer Causes Control 2006, 17:385-394.

29. Smits KM, Gaspari L, Weijenberg MP, Dolzan V, Golka K, Roemer HC, Nedelcheva Kristensen V, Lechner MC, Mehling Gl, Seidegard J, Strange RC, Taioli E: Interaction between smoking, GSTM1 deletion and colorectal cancer: results from the GSEC study. Biomarkers 2003, 8:299-310.

30. Slattery ML, Edwards S, Curtin K, Schaffer D, Neuhausen S: Associations between smoking, passive smoking, GSTM-1, NAT2, and rectal cancer. Cancer Epidemiol Biomarkers Prev 2003, 12:882-889.

31. Gertig DM, Stampfer M, Haiman C, Hennekens CH, Kelsey K, Hunter DJ: Glutathione S-transferase GSTM1 and GSTT1 polymorphisms and colorectal cancer risk: a prospective study. Cancer Epidemiol Biomarkers Prev 1998, 7:1001-1005.

32. Katoh T, Nagata N, Kuroda Y, Itoh H, Kawahara A, Kuroki N, Ookuma R, Bell DA: Glutathione S-transferase M1 (GSTM1) and T1 (GSTT1) genetic polymorphism and susceptibility to gastric and colorectal adenocarcinoma. Carcinogenesis 1996, 17:1855-1859.

33. Harth $V$, Donat $S$, Ko $Y$, Abel J, Vetter $H$, Bruning T: NAD(P)H quinone oxidoreductase 1 codon 609 polymorphism and its association to colorectal cancer. Arch Toxicol 2000, 73:528-531.

34. Hou L, Chatterjee N, Huang WY, Baccarelli A, Yadavalli S, Yeager M, Bresalier RS, Chanock SJ, Caporaso NE, Ji BT, Weissfeld JL, Hayes RB:
CYP1A1 Val462 and NQO1 Ser187 polymorphisms, cigarette use, and risk for colorectal adenoma. Carcinogenesis 2005, 26:1122-1128.

35. Kono S, Toyomura K, Yin G, Nagano J, Mizoue T: A case-control study of colorectal cancer in relation to lifestyle factors and genetic polymorphisms: design and conduct of the Fukuoka colorectal cancer study. Asian Pac J Cancer Prev 2004, 5:393-400.

36. Isomura K, Kono S, Moore MA, Toyomura K, Nagano J, Mizoue T, Mibu R, Tanaka M, Kakeji Y, Maehara Y, Okamura T, Ikejiri K, Futami K, Yasunami Y, Maekawa T, Takenaka K, Ichimiya H, Imaizumi N: Physical activity and colorectal cancer: the Fukuoka Colorectal Cancer Study. Cancer Sci 2006, 97:1099-1104

37. Oyama T, Mitsudomi T, Kawamoto T, Ogami A, Osaki T, Kodama Y, Yasumoto K: Detection of CYP1A1 gene polymorphism using designed RFLP and distributions of CYP1A1 genotypes in Japanese. Int Arch Occup Environ Health 1995, 67:253-256.

38. Arand M, Muhlbauer R, Hengstler J, Jager E, Fuchs J, Winkler L, Oesch F: A multiplex polymerase chain reaction protocol for the simultaneous analysis of the glutathione S-transferase GSTM1 and GSTT1 polymorphisms. Anal Biochem 1996, 236:184-186.

39. Kelsey KT, Ross D, Traver RD, Christiani DC, Zuo ZF, Spitz MR, Wang M, Xu $X$, Lee BK, Schwartz BS, Wiencke JK: Ethnic variation in the prevalence of a common $\mathrm{NAD}(\mathrm{P}) \mathrm{H}$ quinone oxidoreductase polymorphism and its implications for anti-cancer chemotherapy. Br J Cancer 1997, 76:852-854.

40. Sharpe CR, Siemiatycki JA, Rachet BP: The effects of smoking on the risk of colorectal cancer. Dis Colon Rectum 2002, 45:1041-1050.

41. Tajima K, Tominaga S: Dietary habits and gastro-intestinal cancers: a comparative case-control study of stomach and large intestinal cancers in Nagoya, Japan. Jpn J Cancer Res 1985, 76:705-716.

42. Hoshiyama Y, Sekine T, Sasaba T: A case-control study of colorectal cancer and its relation to diet, cigarettes, and alcohol consumption in Saitama Prefecture, Japan. Tohoku J Exp Med 1993, 171:153-165.

43. Martínez C, Martín F, Fernández JM, García-Martín E, Sastre J, Díaz-Rubio M, Agúndez JA, Ladero JM: Glutathione S-transferases mu 1, theta 1, pi 1 , alpha 1 and mu 3 genetic polymorphisms and the risk of colorectal and gastric cancers in humans. Pharmacogenomics 2006, 7:711-718.

44. van der Logt EM, Bergevoet SM, Roelofs HM, Te Morsche RH, Dijk Y, Wobbes T, Nagengast FM, Peters WH: Role of epoxide hydrolase, $\mathrm{NAD}(\mathrm{P}) \mathrm{H}$ :quinone oxidoreductase, cytochrome P450 2E1 or alcohol dehydrogenase genotypes in susceptibility to colorectal cancer. Mutat Res 2006, 593:39-49.

45. Hagiwara T, Kono S, Yin G, Toyomura K, Nagano J, Mizoue T, Mibu R Tanaka M, Kakeji Y, Maehara Y, Okamura T, Ikejiri K, Futami K, Yasunami Y, Maekawa T, Takenaka K, Ichimiya H, Imaizumi N: Genetic polymorphism in cytochrome P450 7A1 and risk of colorectal cancer: the Fukuoka Colorectal Cancer Study. Cancer Res 2005, 65:2979-2982.

46. Moyer AM, Salavaggione OE, Hebbring SJ, Moon I, Hildebrandt MA, Eckloff BW, Schaid DJ, Wieben ED, Weinshilboum RM: Glutathione S-transferase $\mathrm{T} 1$ and M1: gene sequence variation and functional genomics. Clin Cancer Res 2007, 13:7207-7216.

47. Agúndez JA, Ladero JM: Glutathione S-transferase GSTT1 and GSTM1 allozymes: beyond null alleles. Pharmacogenomics 2008, 9:59-363.

\section{Pre-publication history}

The pre-publication history for this paper can be accessed here: http://www.biomedcentral.com/1471-2407/10/274/prepub

doi: $10.1186 / 1471-2407-10-274$

Cite this article as: Nisa et al., Cigarette smoking, genetic polymorphisms and colorectal cancer risk: the Fukuoka Colorectal Cancer Study BMC Cancer 2010, 10:274 